\title{
Refrigerante: uma temática de incentivo para o processo de ensino aprendizagem na disciplina de Ciências
}

\author{
Soda: a thematic of incentive to the teaching and learning process in \\ sciences
} Gilvanice Soares Fernandes Lopes ${ }^{1}$; Júlio da Silva Oliveira²; Leandro Carbo ${ }^{3}$; André Berton ${ }^{4}$;
Edione Teixeira de Carvalho

1 Graduada, Instituto Federal de Mato Grosso/Campus São Vicente/Centro de Referência de Jaciara, Jaciara, Mato Grosso, Brasil - gilvanice01@gmail.com,/https://orcid.org/0000-0002-4730-930X

2 Graduado, Instituto Federal de Mato Grosso/Campus São Vicente/Centro de Referência de Jaciara, Jaciara, Mato Grosso, Brasil - julio.silvastu@gmail.com,/https://orcid.org/0000-0003-3281-2268

3 Doutor, Instituto Federal de Mato Grosso, Jaciara, Mato Grosso, Brasil - leandro.carbo@svc.ifmt.edu.br,/ https://orcid.org/0000-0001-5514-7040

4 Mestre, Instituto Federal de Mato Grosso/Campus São Vicente/Centro de Referência de Campo Verde, Campo Verde, Mato Grosso, Brasil - andre.berton@svc.ifmt.edu.br,/https://orcid.org/0000-0003-0076-4310

5 Doutora, Instituto Federal de Mato Grosso, Campo Verde, Mato Grosso, Brasil - edione.carvalho@svc.ifmt.edu.br,/ https://orcid.org/0000-0002-1208-3961

\section{Recebido em 26/04/2018. Publicado em Agosto/2019}

Palavras-chave:

Ensino de Ciências.

Refrigerante. Atividades

Práticas. Atividades

Lúdicas.
RESUMO: Neste trabalho, foram aplicadas metodologias diferenciadas, com base em aulas experimentais e dinâmicas, sobre a temática do refrigerante no contexto da disciplina de Ciências, em uma escola municipal de Jaciara, Mato Grosso. Foram realizadas aulas expositivas e atividades práticas e lúdicas para alunos do $8 .^{\circ}$ e $9 .^{\circ}$ anos do Ensino Fundamental. Em primeiro lugar, foi aplicado um questionário de maneira a obter informações referentes ao consumo de refrigerante e a identificar o conhecimento prévio dos alunos sobre o tópico. Nas aulas expositivas e dialogadas, foram abordados aspectos sobre essa bebida, tais como processo de fabricação, composição química e efeitos nocivos à saúde. Foi produzido um material pedagógico e, em seguida, foram realizados experimentos associados aos conteúdos das aulas de Ciências. Os resultados mostram que a união da teoria à prática, de forma contextualizada, por meio da inserção da temática do refrigerante, contribuiu positivamente para o processo de ensino-aprendizagem, permitindo uma melhor compreensão dos assuntos abordados.

ABSTRACT: In this work, particular methodologies were applied, based on experimental and dynamic experiments, regarding the subject of the beverage soda in the context of Sciences, in a municipal school in Jaciara, Mato Grosso. Lectures and practical and playful activities were carried out for $8^{\text {th }}$ and $9^{\text {th }}$ grade students. Firstly, a questionnaire was applied in order to obtain the information related to the consumption of soda and identify students' prior knowledge on the topic. In the lectures, interactive classes, aspects of this drink were exposed, such as production process, chemical composition and harmful effects on health. A teaching material was produced and, after that, experiments related to the science classes were carried out. The results show that the combination of theory and practice, in a contextualized way, through the insertion of the of the topic of soda, contributed positively to the teaching and learning process, allowing a better understanding of the subjects covered. 


\section{INTRODUÇÃO}

A necessidade de conhecer os fenômenos naturais e as suas transformações para solucionar problemas postos pela Ciência requer metodologias que promovam a articulação entre os saberes já existentes, para que ocorra efetivamente um novo conhecimento. Nesse sentido, utilizar a experimentação como metodologia na disciplina de Ciências corrobora com as instruções dos Parâmetros Curriculares Nacionais (PCN), sendo uma estratégia que explora as informações e as contextualiza na prática (BRASIL, 1998). De fato, as atividades experimentais possibilitam a articulação entre os conteúdos e os acontecimentos reais, contribuindo para a construção do conhecimento. Taha et al. (2016) relatam que o experimento não se aplica a resultados previamente estabelecidos, pois é precisamente a falta de respostas que incentiva os questionamentos, tornando, assim, a prática educativa.

A experimentação tem contribuído muito para a aprendizagem de conteúdos, principalmente na disciplina de Ciências, como relatado por Bevilacqua e Silva (2007) e Malacarne e Strieder (2009). Segundo Agioni (2005), a experimentação foi defendida por Aristóteles há cerca de 3200 anos. O filósofo grego argumentava que o ser humano que tivesse a noção do saber sem a experimentação, na verdade, ignoraria as particularidades de tais saberes.

A experimentação também é essencial para despertar o interesse dos alunos nas aulas de Ciências e incentivá-los a pensar, promovendo oportunidades de relacionar as teorias com os acontecimentos do cotidiano. Para tanto, é necessário que o professor elabore um planejamento dos assuntos a serem trabalhados nas atividades experimentais. Conforme destacam Reginaldo, Sheid e Gullich (2012), os docentes devem buscar informações e tecnologias a serem aplicados em sala de aula. Eles devem ajudar os alunos a elaborar hipóteses e contribuir para que eles ampliem seus conhecimentos.

Para o desenvolvimento desta pesquisa, optou-se pela temática da bebida refrigerante, pois trata-se de um tópico que constitui uma importante ferramenta e contribui para a contextualização de conceitos no ensino de Ciências. O refrigerante é uma das bebidas mais consumidas na atualidade, o que pode ser explicado pelo seu sabor característico. Outro ponto observado é que, por ser um produto versátil, de baixo custo e de fácil acesso, essa bebida constitui um veículo prático para abordar teorias científicas, permitindo diversas possibilidades de experimentos investigativos.

Diante do contexto apresentado, o objetivo deste trabalho foi o de avaliar como atividades práticas contextualizadas relacionadas ao tema do refrigerante podem auxiliar no processo de ensino-aprendizado na disciplina de Ciências para alunos do $8 .^{\circ}$ e $9 .^{\circ}$ anos. 
Ensino, Saúde e Ambiente - V12 (2), pp. 103-120, Ago. 2019

\section{ENSINO DE CIÊNCIAS NO BRASIL}

A Ciência sempre esteve presente na sociedade, contribuindo muito para o desenvolvimento da humanidade. Durante a Revolução Industrial, ela foi essencial e após a Segunda Guerra Mundial o reconhecimento da sua relevância foi acentuado. As várias linhas de pensamento a respeito do uso da ciência vinculada à tecnologia têm presença marcante nos documentos curriculares acerca do processo de ensino-aprendizagem.

Com as mudanças no ensino de Ciências, orientadas pela influência da Nova Escola, o aluno passou a ocupar uma posição de destaque na construção do conhecimento, ou seja, o professor deixa de ser o eixo central e passa a ser mediador no processo de ensinoaprendizagem. Nesse sentido, os cursos de licenciaturas começaram a desenvolver práticas pedagógicas e investigativas como procedimento de contextualização do conhecimento científico trabalhado nas aulas de Ciências. Essa passou a ser vista como a única estratégia para o ensino dessa disciplina (BRASIL, 1998).

Nas aulas de Ciências, o aluno é submetido a uma determinada situação-problema, devendo solucioná-la e chegar a uma conclusão que necessariamente já existia. Desse modo, a postura exigida nessas aulas era a do pesquisador, do sujeito ativo a elaborar metodologias científicas para poder chegar a um determinado resultado. A metodologia de aprendizagem estava enraizada em uma teoria construtivista, ou seja, ter experiência e vivenciar o momento, a situação.

Numa visão contemporânea sobre os novos conceitos que possibilitam integrar conteúdo e aprendizagem, o professor deve propor aulas mais atrativas. Drehmer e Rosa (2012) sugerem que a experimentação seja usada como ferramenta que possibilita ao aluno refletir, questionar e expor o assunto estudado. Segundo Mendonça e Zanon (2017), nesse modelo de aprendizagem, os experimentos investigativos não se limitam apenas à observação, mas permitem que os estudantes sejam conscientes da apropriação dos conhecimentos científicos e da complexidade dos processos evolutivos. O professor deve participar como mediador nessa construção do conhecimento.

De acordo com Sousa et al. (2014), professores de escolas públicas relatam que o uso de atividades práticas e de aulas experimentais tem apresentado um melhor resultado no aprendizado dos alunos. Com a associação entre a teoria e a prática, eles passam a demonstrar maior interesse e curiosidade pelos conteúdos. Nesse contexto, destacam-se alguns autores que defendem essa metodologia de ensino: Wilsek e Tosin (2012), Souza (2013), Reginaldo, Sheid e Gullich (2012). 
Ensino, Saúde e Ambiente - V12 (2), pp. 103-120, Ago. 2019

\section{A EXPERIMENTAÇÃO NO ENSINO DE CIÊNCIAS}

Optar pelo uso da experimentação como alternativa de construção do conhecimento científico estimula o espírito investigativo no aluno. A compreensão dos assuntos abordados está diretamente ligada aos conceitos científicos vinculados por meio da prática. Isso permite que o estudante desenvolva habilidades como, por exemplo, a percepção, o questionamento e a associação dos fenômenos com o cotidiano. Conforme afirmam Lauxen, Wirzbicki e Zanon (2007),

A investigação nunca se restringe a observações empíricas nem tampouco se limita ao caráter descritivo, justificando-se a importância de atividades práticas desenvolvidas com intencionalidade deliberada de mediar processos de apropriação de linguagens e significados teórico-conceituais impossíveis de serem construídos de forma direta, pelos estudantes. (LAUXEN; WIRZBICKI, ZANON, 2007, p. 5).

Segundo essa mesma linha de raciocínio, é necessário estimular mais reflexão durante a realização de atividades práticas. De fato, a experimentação não se deve limitar apenas à reprodução do fenômeno estudado. De acordo com Pereira (2010), o ensino de Ciências tende ao fracasso por impor apenas práticas tecnicistas, nas quais se espera chegar a um único resultado.

A experimentação é uma importante metodologia de ensino, com a qual o professor aplica o conteúdo, vinculando-o a aspectos de vida do aluno, para que este possa chegar à compreensão de problemas que têm relação com a sua realidade imediata. Guimarães (2009) salienta a necessidade de o educador tomar algumas providências no sentido de estimular a motivação, o trabalho em equipe e a cooperação.

A construção do conhecimento por meio da experimentação no ensino de Ciências não se limita apenas a um processo investigativo, com a verificação de teorias científicas ao final. Trata-se de um conjunto de ações que devem também ser incluídas no processo de aprendizagem, tais como observação, questionamentos, acertos, erros, hipóteses, materiais manipulados, comunicação e expressão, conforme listam Zanon e Freitas (2007).

Nos conteúdos presentes nos PCN, mais especificamente os do terceiro e quarto ciclos do Ensino Fundamental, no bloco "Ser Humano e Saúde" (BRASIL, 1998, p. 73), são abordados os hábitos alimentares. Destaca-se o consumo de algumas bebidas doces que fazem mal à saúde - entre elas, está o refrigerante. Ele é um exemplo de ferramenta de ensino que permite várias possibilidades de experimentação e possibilita abordar vários conceitos científicos de áreas variadas, como Física, Química e Biologia.

\section{A TEMÁTICA DO REFRIGERANTE NO ENSINO DE CIÊNCIAS}

Neste mundo globalizado, que instiga o consumismo, os indivíduos são constantemente bombardeados por propagandas que oferecem produtos tecnológicos ou 
alimentícios sobre os quais pouco se conhece. Nesse contexto, o ensino de Ciências emerge como fonte de conhecimento para a formação de um cidadão crítico e autônomo em suas decisões. Compreender o próprio corpo é fundamental para o cidadão ter uma boa qualidade de vida e adquirir hábitos alimentares saudáveis. Sendo assim, abordar assuntos que visam ao entendimento sobre a alimentação permite que o indivíduo faça escolhas sadias, em detrimento das várias opções de alimentos que ameaçam a saúde humana. Dentre essas possibilidades, podem ser citadas as guloseimas, os sanduíches, os doces e os refrigerantes, que têm apelo principalmente para as crianças e adolescentes.

Conforme já foi adiantado, a temática do refrigerante constitui uma importante ferramenta metodológica, que contribui para a contextualização de conceitos no ensino de Ciências. Por ser um produto versátil, de baixo custo e de fácil acesso, permite abordar teorias científicas com diferentes possibilidades de experimentos investigativos para os alunos.

De acordo com o artigo 23 do Decreto n. ${ }^{\circ}$ 6.871, o refrigerante é uma bebida gaseificada, obtida pela dissolução, em água potável, de suco ou extrato vegetal de sua origem, mistura à qual é adicionado açúcar (BRASIL, 2009). Portanto, trata-se de uma bebida doce. A presença de gás carbônico $\left(\mathrm{CO}_{2}\right)$ contribui para o efeito refrescante, muito atrativa para o consumo (SILVA; KEMMERICH; MARTINS, 2010). De acordo com Carmo et al. (2006), crianças e adolescentes têm consumido muitas bebidas com adição de açúcar, incluindo os refrigerantes, sendo esta uma das principais causas de obesidade, doença considerada uns dos maiores problemas de saúde pública da população da atualidade.

Dados do Estudo Nacional de Despesa Familiar (Enedf) e da Pesquisa de Padrão de Vida (PPV), citados por Carmo et al. (2006) e Veiga, Cunha e Sichieri (2004), indicam que, no Brasil, os índices de obesidade entre os jovens são alarmantes. Além da obesidade, Flores et al. (2013), Souza (2014) e Tomaz, Ramos e Mendes (2014) relatam algumas problemáticas devido ao consumo excessivo de produtos industrializados como o refrigerante. Entre esses problemas estão a ansiedade, o aumento de doenças crônica não transmissíveis (DCNT), a dependência, o surgimento de tumores malignos e a osteoporose.

Considerando os maus hábitos alimentares de jovens e adolescentes, é importante fomentar estudos sobre os riscos dos refrigerantes para a saúde. As aulas de Ciências podem constituir um espaço privilegiado para isso, ajudando os alunos a conseguir uma melhor qualidade de vida.

\section{MATERIAL E MÉTODOS}

Este trabalho foi realizado com duas turmas do ensino fundamental do $8 .^{\circ}$ e do $9 .^{\circ}$ anos, respectivamente com 26 e 30 alunos, nos meses de outubro e novembro de 2017 , em uma escola municipal na cidade de Jaciara, em Mato Grosso. Para a escolha dessa escola, 
levou-se em consideração a realização dos estágios do curso de Licenciatura em Ciências da Natureza (Estágio Supervisionado II - Estudos de documentos, Estágio Supervisionado III Observação de aulas e Estágio Supervisionado IV - Regência), nos quais foi constatada a necessidade de trabalhar metodologias diferenciadas na disciplina de Ciências, de forma a melhorar a construção de conhecimento dos alunos sobre os conteúdos abordados na disciplina, relacionando-os ao cotidiano. Trata-se de uma pesquisa qualitativa que se enquadra em estudo de caso (ANDRÉ, 2013). O tema do refrigerante foi inserido em um contexto social, levando em consideração a construção do conhecimento. A condução do tema foi baseada em observações, socialização de saberes, realização de aulas expositivas/dialogadas e experimentação.

No ambiente educacional, o conhecimento é construído por meio das atitudes das pessoas no meio no qual elas estão inseridas, o que envolve resultados não fixo e acabados, mas sujeitos a mudanças constantes. André (2013) defende que o pesquisador deve fazer uma interpretação pessoal por meio de uma investigação social. É o contato com o ambiente e as pessoas que permite descrever ações e comportamentos.

Levando isso em consideração, procurou-se o professor de Ciências da Escola Municipal Magda Ivana, que está localizada no bairro Jardim Aeroporto. O professor forneceu aos pesquisadores os livros didáticos da disciplina. Analisando o conteúdo programático e considerando os PCN (BRASIL, 1998), observou-se a possibilidade de utilizar uma temática inserida no contexto das aulas de Ciências para abordar conceitos químicos e biológicos.

Uma das técnicas de levantamento de dados para a realização da pesquisa foi a utilização do questionário. Conforme afirma Gil (2008), o questionário é uma investigação composta de perguntas, a fim de se obter conhecimentos prévios, opiniões, sentimentos e visões sobre situações do cotidiano por parte dos investigados.

\section{AVALIAÇÃO DO CONSUMO DE REFRIGERANTE}

Aplicou-se um questionário prévio nas turmas de $8 .^{\circ}$ e $9 .^{\circ}$ anos, contendo questões objetivas e dissertativas, de forma a avaliar o nível de conhecimento e a frequência de consumo por parte do público-alvo de bebidas gaseificadas (refrigerantes). De forma mais específica, em relação às questões aplicadas, foram considerados os seguintes aspectos: frequência de consumo, tipo de refrigerante que mais consumiam, momento de maior consumo, quantidade de copos de refrigerante que consumiam e conhecimentos sobre os malefícios que a bebida causa ao organismo.

Em seguida, realizou-se a problematização da temática de estudo por meio de perguntas-problema. Foi realizada uma abordagem teórica sobre o processo de fabricação do 
Ensino, Saúde e Ambiente - V12 (2), pp. 103-120, Ago. 2019

refrigerante. Com base nos rótulos, foi feita uma apresentação visual sobre as funções de cada componente presente na composição química da bebida. Foram enfatizadas as principais diferenças entre refrigerantes diet, light e zero e elencados os efeitos nocivos de cada tipo para a saúde humana. Desse modo, os discentes foram sensibilizados em relação ao consumo excessivo e aos malefícios causados pelo refrigerante. Recorreu-se à exposição de imagens para uma melhor apresentação dos conceitos. Ao todo, foram desenvolvidas oito aulas, sendo quatro em cada turma $-8 .^{\circ}$ e $9 .^{\circ}$ anos.

Como forma de avaliar a aprendizagem na atividade proposta, foram entregues aos alunos do $8 .^{\circ}$ ano os seguintes itens: cartolina, lápis, borracha, lápis de cor, pincel, régua e tintas guache. Eles deveriam desenvolver cartazes informativos a partir dos conhecimentos obtidos nas aulas ministradas, alertando a comunidade sobre os efeitos nocivos à saúde do consumo excessivo de refrigerante. Já com a turma do 9. ${ }^{\circ}$ ano, em uma área aberta, foi realizado o experimento intitulado "Explosão da Química do refrigerante". O objetivo era observar o fenômeno do spray.

Os refrigerantes foram numerados e etiquetados em seus recipientes com as informações: tipo de refrigerante (normal ou zero), volume ocupado (600 mL, 1,5 L, 2,0 L e 2,5 L) e temperatura (quente ou frio). As garrafas foram colocadas lado a lado, a fim de formar uma fileira, com uma distância de $30 \mathrm{~cm}$ uma da outra. Uma bala de menta foi introduzida em todos os refrigerantes simultaneamente. Após a realização da atividade prática, os alunos foram indagados com questionamentos (perguntas-problema), de acordo com o fenômeno observado.

\section{RESULTADOS E DISCUSSÃO}

\section{ANÁLISE DO QUESTIONÁRIO APLICADOS AOS ALUNOS}

Após a análise dos questionários aplicados às duas turmas ( $8 .^{\circ}$ e $9 .^{\circ}$ anos $)$, verificouse que o consumo de refrigerante era constante na vida dos alunos. Wirth (2010), Lima e Afonso (2009) afirmam que as bebidas industrializadas, principalmente os refrigerantes, são muito presentes na sociedade contemporânea. Tal consumo é facilitado por se tratar de um produto de fácil acesso e baixo custo.

A Figura 1 mostra que os alunos do $8 .^{\circ}$ ano possuem frequência de consumo maior quando comparados aos do $9 .^{\circ}$ ano. É importante salientar que 15 discentes do $8 .^{\circ}$ ano e 25 do $9 .^{\circ}$ ano responderam ao questionário. A comparação mostra que os alunos mais jovens se relacionam mais com a mídia (TVs, smartphones e internet, entre outros meios). Dessa forma, podem ser mais induzidos a consumir determinados produtos industrializados, como os refrigerantes. 


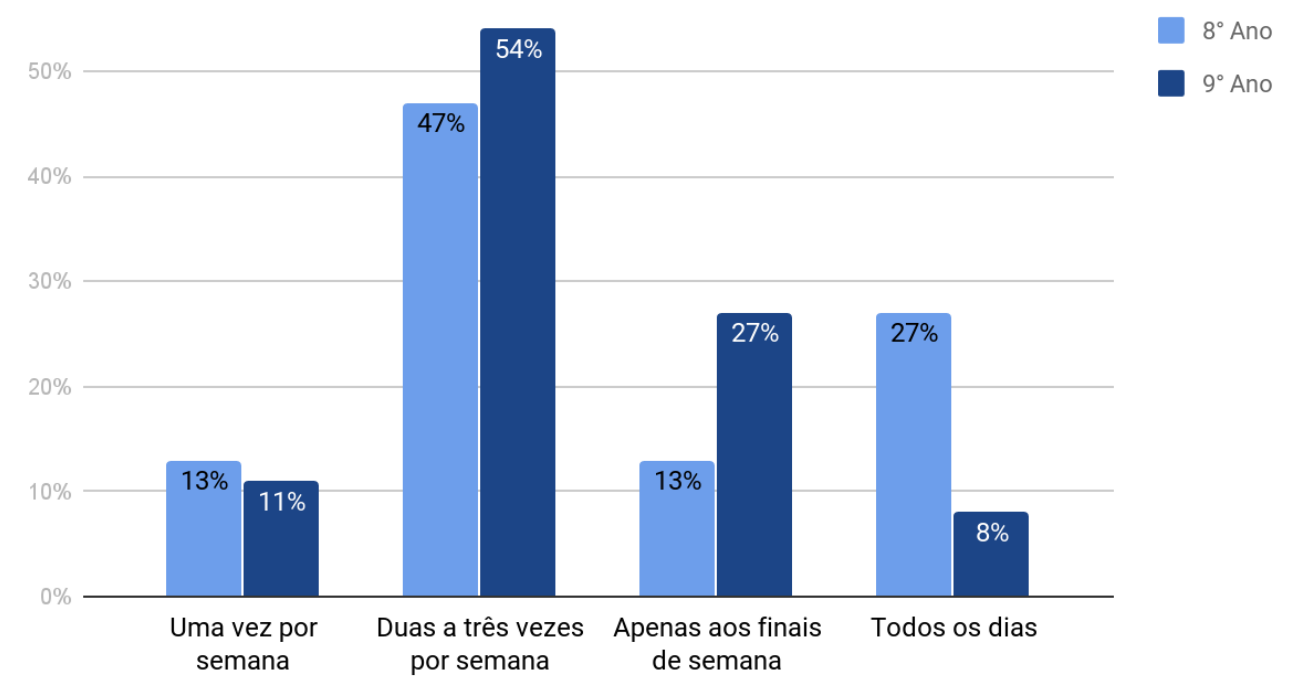

Figura 1- Frequência de consumo de refrigerante pelos alunos do $8 .^{\circ}$ e $9 .^{\circ}$ anos

Fonte: Dados da pesquisa

Sichieri e Souza (2008) realizaram uma pesquisa que apresenta dados semelhantes. Os autores mostraram que os jovens estão consumindo cada vez mais calorias. Imersos no sedentarismo, eles são protagonistas do marketing de indústrias de alimentos, das propagandas de TVs e das cadeias de fastfood. Casotti et al. (1998) também adotam a mesma linha de argumentação ao afirmarem que as mudanças de hábitos alimentares estão fortemente associadas à evolução e às formas de distribuição dos alimentos com a ajuda do marketing.

As respostas fornecidas pelos alunos do $8 .^{\circ}$ ano indicam que $47 \%$ consomem refrigerantes duas a três vezes por semana - os tipo Guaraná e Cola apresentam cada um 39\% das ocorrências. A bebida é consumida ao almoço e ao jantar, com $44 \%$ e $28 \%$, respectivamente. Sobre a quantidade, $40 \%$ consomem de quatro a cinco copos, o que faz com que a ingestão de açúcar superior seja à da turma do $9 .^{\circ}$ ano. A respeito dos malefícios, $60 \%$ afirmaram não ter conhecimento sobre isso.

As respostas dos alunos do $9 .^{\circ}$ ano mostram que $54 \%$ dos respondentes alegaram consumir refrigerantes duas a três vezes por semana, sendo que $27 \%$ optam por Guaraná. Sobre o momento de consumo, na maioria das vezes, a bebida acompanha o almoço e o jantar, com $41 \%$ e $27 \%$, respectivamente. Sobre a quantidade, $88 \%$ alegaram beber de dois a três copos de refrigerante. $21 \%$ afirmaram ter conhecimento de algum malefício que a bebida pode causar para a saúde.

Autores como Dalmolin, Peres e Nogueira (2012), Estima et al. (2011), Oliveira et al. (2011) e Willet (2001) apresentam resultados semelhantes ao do presente trabalho e alertam sobre os malefícios do refrigerante à saúde. Apesar de os estudantes do presente 
trabalho afirmarem que consomem muito refrigerante, Cancian (2015), em artigo publicado no jornal Folha de São Paulo, o consumo desta bebida nos últimos seis anos tem diminuído em torno de $20 \%$ entre os brasileiros. Tal afirmação sugere que as pessoas estão mais informadas e tornando-se conscientes sobre as problemáticas ocasionadas pelo consumo de bebidas açucaradas, como também alertam os autores Dalmolin, Peres e Nogueira (2012), Mariz et al. (2013) e Carvalho (2006). De certa forma, as publicações científicas sobre a temática proposta têm apresentado impactos significativos na sociedade, instruindo as pessoas e levando-as a mudanças comportamentais por meio de argumentos fortes.

Recentemente, uma matéria da Época Negócios Online (2017) revelou que uma das maiores companhias de refrigerantes do mundo propôs um desafio para a comunidade científica: encontrar um composto de origem natural, com nenhuma ou baixas calorias, que possa substituir o açúcar do refrigerante. Apesar de a revista argumentar a preocupação das maiores produtoras de refrigerante a respeito do açúcar, não é citado na reportagem nenhum trabalho realizado sobre esse assunto. De todo modo, tal proposta demonstra a preocupação dos fabricantes com a diminuição do consumo de bebidas não alcoólicas, carbonatadas e com alto poder refrescante, o que, obviamente, representa prejuízos financeiros para as indústrias.

Abordar temáticas sobre alimentos saudáveis é uma ferramenta de aprendizagem que se aproxima da realidade dos jovens e contribui para a formação de cidadãos críticos e autônomos de suas escolhas, levando-os a não serem presas fáceis do mercado consumista e de propagandas enganosas.

\section{AULAS DIALOGADAS, CONFECÇÃO DOS CARTAZES E ATIVIDADE PRÁTICA}

Nas aulas ministradas nas duas turmas sobre a temática do refrigerante, os alunos demonstraram curiosidade pelo tópico em questão, por se tratar de um assunto que está presente no cotidiano desse público. Entretanto, percebeu-se que eles desconheciam as consequências do consumo excessivo dessa bebida. Sobre a relação entre a vivência dos alunos e os conteúdos ministrados na escola, Masetto (1997, p. 35) afirma que:

\footnotetext{
Quando o aluno percebe que pode estudar nas aulas, discutir e encontrar pistas e encaminhamentos para questões de sua vida e das pessoas que constituem seu grupo vivencial, quando seu [sic] dia-a-dia de estudos é invadido e atravessado pela vida, quando ele pode sair da sala de aula com as mãos cheias de dados, com contribuições significativas para os problemas que são vividos "lá fora", este espaço se torna espaço de vida, a sala de aula assume um interesse peculiar para ele e para seu grupo de referência.
}

Durante a apresentação dos conteúdos, os alunos fizeram vários questionamentos, resultado da interação conjunta na construção do conhecimento. Isso demonstra o que Paulo Freire (1971, p. 36) afirma sobre as aulas expositivas dialogadas, que estimulam a participação efetiva dos alunos, tornando-se mais produtivas: "Na dialogicidade, na problematização, educador-educando e educando-educador vão ambos desenvolvendo uma 
postura crítica da qual resulta a percepção de que este conjunto de saber se encontra na interação".

De fato, a aprendizagem torna-se mais interessante e significativa quando possibilita uma interação entre os participantes da aula, promovendo espaços para falas individuais e diálogos com outros sujeitos. A escola promove, assim, um momento enriquecedor, a partir de envolvimento de todos em situações desafiadoras, num contínuo processo de construção de novas ideias. Esse processo de diálogo com outras pessoas permite uma elaboração pessoal de significados e não mera reprodução ou repetição de informações - modelo que existe persiste em algumas aulas.

Catalan e Angeles (2001, p. 53) afirmam que "as pessoas criam significados com base na definição particular que fazem do contexto e em suas experiências prévias em diferentes contextos socioculturais". Seguindo essa linha de pensamento, durante as aulas realizadas com as duas turmas, houve uma interação conjunta dos alunos e cada um expôs a sua opinião a partir dos seus conhecimentos prévios. Todos compartilharam informações que levaram a um profundo envolvimento na temática proposta; assim, novos entendimentos foram sendo construídos entre os participantes nas aulas de Ciências. Ramos e Moraes (2009, p. 02) relatam os meios que propiciam uma aprendizagem e destacam a importância da fala:

\begin{abstract}
Aprendemos quando nos comunicamos, quando falamos e quando ouvimos os outros, pois, nesses processos nossos entendimentos são questionados e transformados, com acréscimo de novos entendimentos e significados. Aprender faz parte do viver e enquanto vivemos estamos constantemente ampliando nossos entendimentos e representações do mundo em que vivemos. Aprender significa envolver-se em movimentos constantes de transformação e evoluir progressivamente em representações já anteriormente construídas. Nesse sentido, ao valorizarem-se as falas e manifestações dos alunos em sala de aula, pretende-se, além de expressar o conhecido, atingir modos mais elaborados de entendimento.
\end{abstract}

Valorizar a fala dos alunos em sala de aula é o caminho inicial para alcançar uma aprendizagem que leve em conta o contexto sociocultural no qual estão inseridos. Nesse sentido, ressalta-se a importância de o professor saber articular os conhecimentos como mediador, direcionando os alunos por caminhos desconhecidos para que possam ampliar seus conhecimentos. Foi esse o percurso desenvolvido no presente trabalho, quando questionamos os alunos por meio de perguntas-problemas.

A partir dos conceitos abordados sobre a composição química do refrigerante, foi promovida uma discussão a respeito das principais doenças relacionadas aos componentes presentes nessa bebida. Conforme afirma Souza Júnior (2015), o refrigerante é uma problemática que está diretamente interligada ao meio social dos alunos e isso facilita uma abordagem em sala de aula, explorando conceitos diferenciados.

Os questionamentos iniciaram-se após a exposição de algumas doenças comuns, como a obesidade, causada devido à grande quantidade de açúcar nos refrigerantes. Segundo 
Dalmolin, Peres e Nogueira (2012), o público jovem é o maior consumidor de açúcar; em consequência disso, há doenças alarmantes entre esse público. Apresentar os riscos provocou nos alunos uma reflexão sobre seus hábitos e sobre suas escolhas.

Com o objetivo de avaliar os conhecimentos aprendidos nas aulas dialogadas/expositivas, os alunos foram divididos em grupos e, em seguida, houve momentos de socialização de informações e ideias para o desenvolvimento dos trabalhos. Aplicar aulas ilustrativas com metodologias diferenciadas é uma prática positiva. Contudo, Taha et al. (2016) argumentam que a atividade experimental ilustrativa pode, sim, ser significativa, desde que contribua para a construção do conhecimento.

Foi possível observar que a atividade sobre a confecção dos cartazes despertou o envolvimento dos alunos e eles participaram ativamente nela. Os trabalhos proporcionaram a partilha de conhecimentos e a associação dos conceitos teóricos à prática. De forma espontânea, os alunos assumiram uma postura positiva no processo de ensino e aprendizado. A propósito disso, Paula et al. (2017, p. 02) consideram que a prática não somente completa a teoria, mas “estabelece novas percepções aos alunos em relação à disciplina, contribuindo para aprendizagem, a experimentação entendida enquanto prática, juntamente com os conceitos teóricos, potencializa a construção do conhecimento". As Figuras 2 e 3 mostram cartazes feitos pelos alunos.

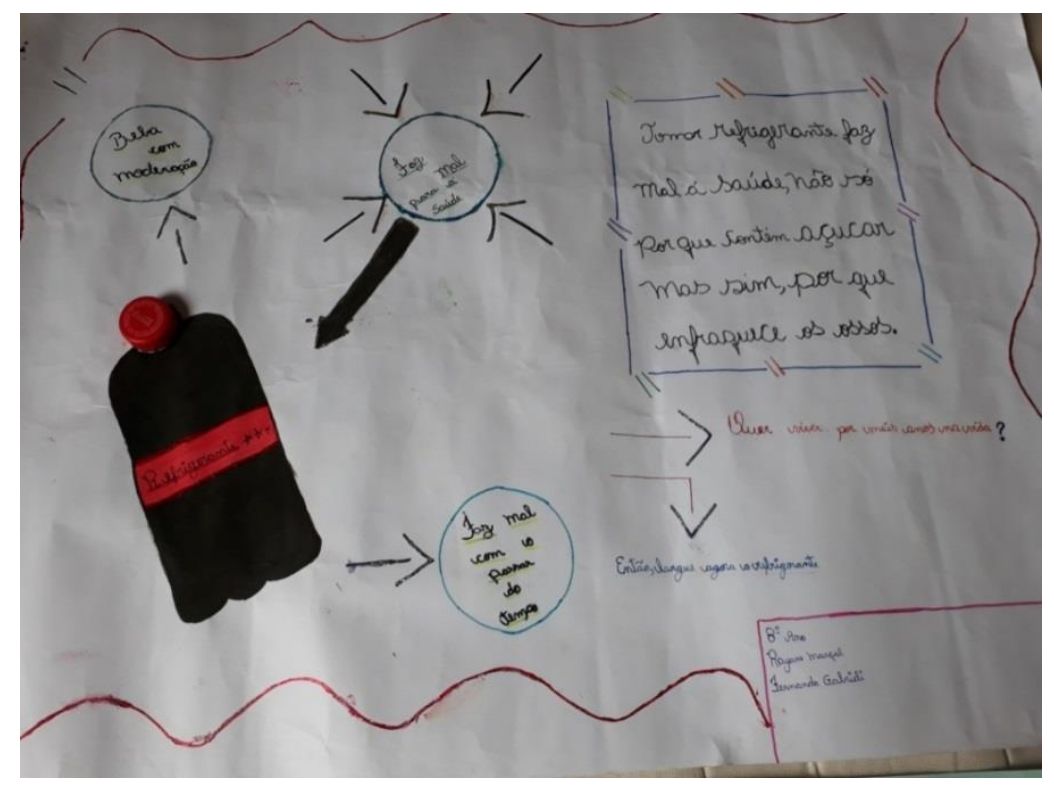

Figura 2 - Cartaz feito pelos alunos do $8 .^{\circ}$ ano sobre a temática refrigerante

Fonte: Dados da pesquisa

Os cartazes dos alunos informam as consequências que os refrigerantes trazem à saúde. Eles mencionam doenças como a obesidade e o diabetes e problemas como cáries dentária, insônia, irritabilidade e fraqueza dos ossos. Essas consequências foram debatidas 
Ensino, Saúde e Ambiente - V12 (2), pp. 103-120, Ago. 2019

durante as aulas expositivas/dialogadas. Por meio dessas atividades, observou-se que os alunos demonstraram a capacidade de se apropriar dos conhecimentos discutidos em sala.

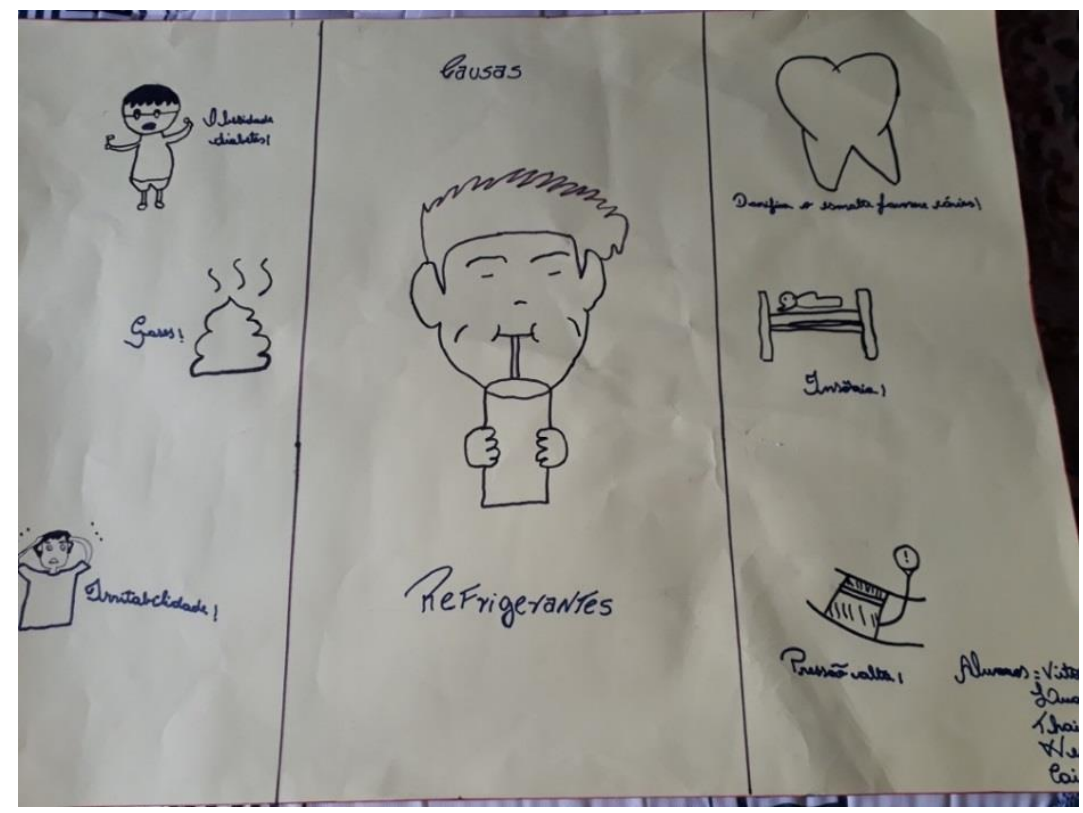

Figura 3 - Cartaz feito pelos alunos do $8 .^{\circ}$ ano sobre a temática refrigerante

Fonte: Dados da pesquisa

Por sua vez, o experimento da explosão da Química do refrigerante (Figura 4), realizado com o $9 .^{\circ}$ ano, pretendeu instigar o espírito investigativo dos alunos. Foram notórias a motivação e a participação de todos antes e durante a ocorrência da prática pedagógica. No entanto, após a experiência, os alunos apresentaram certas atitudes negativas.

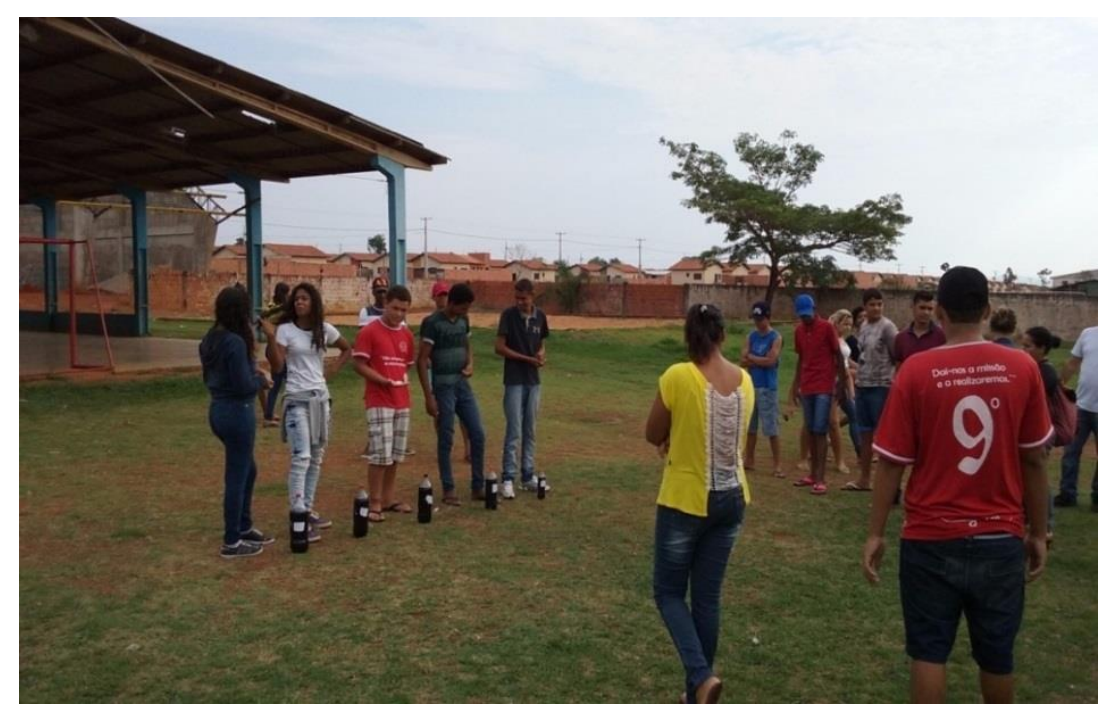

Figura 4 - Experimento "Explosão da Química do refrigerante" com alunos do 9. a ano

Fonte: Dados da pesquisa

Os alunos demonstraram interesse e prazer na aprendizagem antes e durante a realização do experimento. Eles pareciam impressionados pelo apelo visual do experimento e 
encantados com o fenômeno do spray. Contudo, após a atividade experimental, eles se dispersaram e não prestaram atenção à abordagem teórica e científica do experimento. Portanto, percebe-se que nem sempre a experimentação possa trazer resultados positivos. Concordamos com Pires e Machado (2013, p. 166) quando afirmam:

Apesar de a experimentação no ensino [...] ser uma das temáticas mais discutidas por pesquisadores da área de ensino, continuamos a encontrar com facilidade, hoje também na internet, um número crescente de propostas de experimentos desvinculadas de uma abordagem teoricamente orientada e que, por essa razão, nada ou pouco acrescentam ao processo ensino-aprendizagem.

Bachelard (1996, p. 36) relata que, muitas vezes, a nossa sociedade substitui “o conhecimento pela admiração, as ideias pelas imagens" - essa tendência pode explicar o comportamento dos alunos na atividade proposta. Outro fator a se considerar é que esse público está mais habituado ao ensino de Ciências de uma forma tradicional - sala de aula, conteúdo, memorização, foco tecnicista, quadro negro e giz. Dessa forma, as metodologias diferenciadas podem, de início, causar um desconforto e gerar uma resistência.

Em um tópico de seu trabalho intitulado "Resistência ao projeto", Guimarães (2009) relata a fala de alunos que se manifestaram contra o desenvolvimento de atividades experimentais. $\mathrm{O}$ autor justifica-se ao dizer que, quando se pretende inserir uma estratégia pedagógica que fuja às práticas comuns, é necessário ficar atento ao desafio de aliar as metodologias tradicionais às novas propostas de construir o conhecimento - caso contrário, o trabalho pode resultar em fracasso.

Apesar de a atividade proposta ter sido diferenciada, observou-se que não houve muita empolgação por parte dos alunos após o experimento. Nesse sentido, podemos afirmar que a experimentação é, sim, uma ferramenta importantíssima na aprendizagem, mas o seu sucesso depende de cada turma e do perfil dos alunos envolvidos. Não se deve mudar de forma brusca a metodologia de ensino; o professor deve antes inovar de forma lenta para não causar desconforto e efeitos negativos no ensino e na aprendizagem, evitando até mesmo incutir uma visão negativa acerca do trabalho científico.

Apesar desse desinteresse depois do experimento, a temática proposta foi importante. Durante as aulas dialogadas, a atenção dos alunos foi perceptível. Isso demonstra que eles estão acostumados a estar em sala de aula com conteúdos prontos e acabados. Como salienta Guimarães (2009), ainda existem escolas que praticam ensino totalmente tradicional, no qual os alunos recebem o conteúdo pronto em livros e apostilas, incentivando-os apenas à memorização.

\section{CONSIDERAÇÕES FINAIS}

Inserir a temática refrigerante no contexto escolar foi imprescindível para o processo de ensino-aprendizagem proposto e possibilitou abordar uma bebida marcante e presente na 
Ensino, Saúde e Ambiente - V12 (2), pp. 103-120, Ago. 2019

vida dos alunos sob um viés científico, unindo a teoria e a prática pedagógica de forma contextualizada. Além disso, houve a oportunidade de instruir os alunos a respeito de uma boa qualidade de vida diante de estudos de práticas alimentares nas aulas de Ciências.

Destaca-se a disposição dos alunos para trabalhos em grupos e para a cooperação. $\mathrm{O}$ preenchimento dos questionários de forma correta demonstra a preocupação e o comprometimento dos discentes com a atividade. Além disso, a confecção de cartazes informativos e a participação de atividade experimental foram outros aspectos positivos. Percebeu-se que, durante as atividades expositivas/dialogadas, os discentes foram participativos. Eles mostraram-se motivados diante da oportunidade de aprenderem os conteúdos associados ao tema do refrigerante. Com o decorrer das aulas, eles sentiram-se sensibilizados e perplexos em relação a alguns dados associados a essa bebida. Muitos relataram que se sentiam impelidos a deixar de consumir refrigerante.

As atividades práticas e lúdicas foram realizadas com materiais de fácil acesso e baixo custo, encontrados em comércios (papelarias e mercados). Este trabalho evidenciou a importância de abordagem de conteúdos de Ciências que estão presentes no cotidiano dos alunos, incentivando a curiosidade, a reflexão e a socialização dos conhecimentos e promovendo atividades diferenciadas em sala de aula.

\section{REFERÊNCIAS}

ANDRÉ, M. O que é um estudo de caso qualitativo em educação? Revista da FaeebaEducação e Contemporaneidade. v. 22, n. 40, p. 95-103, 2013.

ANGIONI, L. Metafísica de Aristóteles. Livro VII. Caderno de História Filosofia e Ciências. Série 3, v. 15, n. 1, p. 201-221, 2005.

BACHELARD, G. A formação do espírito científico: contribuição para uma psicanálise do conhecimento. Rio de Janeiro: Contraponto, 1996.

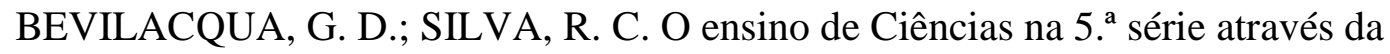
experimentação. Ciências \& Cognição. v. 10, p. 84-92, 2007.

BRASIL. Decreto n. ${ }^{\circ} 6.871$, de 4 de junho de 2009. Regulamenta a Lei n. ${ }^{\circ} 8.919$, de 14 de julho de 1994. Dispõe sobre a padronização, a classificação, o registro, a inspeção, a produção e a fiscalização de bebidas. Diário Oficial [da] República Federativa do Brasil, Poder Legislativo, Brasília, DF, 04 jun. 2009. Disponível em: <https://bit.ly/2JK5pe8>. Acesso em: 17 dezembro de 2017.

BRASIL. Secretaria de Educação Fundamental. Parâmetros Curriculares Nacionais: Ciências Naturais. Brasília: MEC/SEF, 1998.

CANCIAN, N. Em seis anos, brasileiros diminuem consumo de refrigerante em $20 \%$. 2015. Disponível em: <https://bit.ly/2tPqPw7>. Acesso em: 17 dezembro de 2017. 
Ensino, Saúde e Ambiente - V12 (2), pp. 103-120, Ago. 2019

CARMO, M. B.; TORAL, N.; SILVA, M. V.; SLATER, B. Consumo de doces, refrigerantes e bebidas com adição de açúcar entre adolescentes da rede pública de ensino de Piracicaba, São Paulo. Ver. Bras. Epidemiol, v. 9, n. 1, p. 121-130, 2006.

CARVALHO, F. A. C. O livro negro do açúcar: algumas verdades sobre a indústria do açúcar. Rio de Janeiro: Auto Edição, 2006.

CASOTTI, L.; RIBEIRO, A.; SANTOS, C.; RIBEIRO, P. Consumo de Alimentos e Nutrição: dificuldades práticas e teóricas. Revista Cadernos de Debate. v. 6, p. 26-39, 1998.

CATALAN, R.; ANGELES, M. Discurso y educación. Sevilla: Mergablum, D. L., 2001.

DALMOLIN, V. T. S.; PERES, P. E. C.; NOGUERA, J. O. C. Açúcar e educação alimentar: pode o jovem influenciar essa relação? Monografias Ambientais, v. 10, n. 10, p. 2134-2147, 2012.

DREHMER, M.; ROSA, E. A. Os refrigerantes como tema gerador em aulas de Química. O professor PDE e os desafios da escola pública paranaense, v. 1, p. 1-19, 2012. Disponível em: <https://bit.ly/2Te9z30>. Acesso em: 28 agosto de 2017.

ÉPOCA NEGÓCIOS ONLINE. Coca-Cola oferece US\$ 1 milhão para quem resolver seu maior problema. Disponível em: <https://glo.bo/2hRZe74>. Acesso em: 16 novembro de 2017.

ESTIMA, C. C. P.; PHILIPPI, S. T.; ARAKI, E. L.; LEAL, G. V. S.; MARTINEZ, M. F.; ALVARENGA, M. S. Consumo de bebidas e refrigerantes por adolescentes de uma escola pública. Revista Paulista de Pediatria, v. 29, n. 1, p. 41-45, 2011.

FLORES, T. R.; CIOCHETTO, C. R.; NUNES, B. P.; VIEIRA, M. F. A. Consumo de refrigerantes entre escolares de séries iniciais da cidade de Pelotas, Rio Grande do Sul. Revista Ciência \& Saúde. v. 6, n. 1, p. 59-66, 2013.

FREIRE, P. Extensão ou comunicação? 8. ed. Rio de Janeiro: Paz e Terra, 1971.

GIL, A. C. Métodos e técnicas de pesquisa social. 6. ed. São Paulo: Atlas, 2008.

GUIMARÃES, C. C. Experimentação no ensino de Química: caminhos e descaminhos rumo à aprendizagem significativa. Química Nova na Escola. v. 31, n. 3, p. 198-202, 2009.

LAUXEN, M. T. C.; WIRZBICKI, S. M.; ZANON, L. B. O desenvolvimento de currículo de Ciências Naturais no ensino médio numa abordagem contextual e interdisciplinar. In: VI Encontro Nacional de Pesquisa em Educação em Ciências, 2007, Florianópolis. Anais... Florianópolis, resumo 56, 2007.

LIMA, A. C. S.; AFONSO, J. C.; A Química do refrigerante. Química Nova na Escola. v. 31, n. 3, p. 210-215, 2009.

MALACARNE, V.; STRIEDER, D. M. O desvelar da ciência nos anos iniciais do ensino fundamental: um olhar pelo viés da experimentação. Vivências. v. 5, n. 7, p. 75-85, 2009.

MARIZ, L. S.; MEDEIROS, C. C. M.; VIEIRA, C. E. N. K.; ENDERS, B. C.; COURA, A. S. Modificação na frequência alimentar de crianças e adolescentes: acompanhamento em serviço de referência. Revista Latino-Americana de Enfermagem. v. 21, n. 4, p. 01-08, 2013. 
MASETTO, M. T. Didática: a aula como centro. São Paulo: FTD, 1997.

MENDONÇA, J. R.; ZANON, D. A. V. Experimentos investigativos a partir da temática refrigerante no ensino de Ciências. Experiências em Ensino de Ciências. v. 12, n. 3, p. 43$55,2017$.

OLIVEIRA, A. C. S.; SANTOS, E. P.; SILVA, M. S.; VIERIA, T. P. R.; SILVA, S. M. O impacto do consumo de refrigerantes na saúde de escolares do Colégio Gissoni. Revista Eletrônica Novo Enfoque. v. 12, n. 12, p. 68-79, 2011.

PAULA, C.; SABALLA, J.; GUIMARÃES, V.; AZEVEDO, A.; PASTORIZA, B.; SANGIOGO, F. Química e os conceitos de experimentação para o ensino. In: $37 .^{\circ}$ Encontro de Debates sobre o Ensino de Química, n. 37, 2017, Rio Grande. Anais... Rio Grande, p. 01-10, 2017.

PEREIRA, B. B. Experimentação no ensino de Ciências e o papel do professor na construção do conhecimento. Cadernos da Fucamp. v. 9, n. 11, p. 01-09, 2010.

PIRES, D. A. T.; MACHADO, P. F. L. Refrigerante e bala de menta: explorando possibilidades. Química Nova na Escola. v. 35, n. 3, p. 166-173, 2013.

RAMOS, M. G.; MORAES, R. A. Importância da fala na aprendizagem: os diálogos na reconstrução do conhecimento em aulas de Ciências. In: VII Enpec-Encontro Nacional de Pesquisa em Educação em Ciências, 2009, Florianópolis. Anais... Florianópolis, p. 01-12, 2009.

REGINALDO, C. C.; SHEID, N. J.; GÜLLICH, R. I. C. O ensino de Ciências e a experimentação. In: IX Anped Sul: Seminário de Pesquisa em Educação da Região Sul, 2012, Giruá. Anais... Giruá, p. 01-13, 2012.

SICHIERI R.; SOUZA R. A. Estratégias para prevenção da obesidade em crianças e adolescentes. Caderno de Saúde Pública. v. 24, p. 209-234, Supl.02 Debate, 2008.

SILVA, A. M.; KEMMERICH, C.; MARTINS, M. M. Explorando a Química do Refrigerante. In: Responsabilidade Socioambiental - XIV Simpósio de Ensino, Pesquisa e Extensão, n. 14, 2010, Santa Maria. Anais... Santa Maria, p. 01-08, 2010.

SOUSA, F. S.; SILVA, J. S.; PARANHOS, J. D. N.; DANTAS, S. M. M. M. As metodologias usadas por professores de Ciências e Biologia no processo de ensino/aprendizagem. In: V Enebio e II Erebio Regional 1, n. 7, 2014, São Paulo. Anais... São Paulo: Conselho Editorial, p. 2014-2022, 2014.

SOUZA, A. C. A experimentação no ensino de Ciências: importância das aulas práticas no processo de ensino-aprendizagem. 2013. 33 f. Trabalho de Conclusão de Curso (Especialização) - Universidade Tecnológica Federal do Paraná, Medianeira, 2013.

SOUZA, A. D. A. O perigo está servido: abordagem sobre o consumo do chocolate e do refrigerante no ambiente escolar. 2014. 61 f. Trabalho de Conclusão de Curso (Especialização em Fundamentos da Educação: Práticas Pedagógicas Interdisciplinares) - Universidade Estadual da Paraíba, Monteiro, 2014. 
Ensino, Saúde e Ambiente - V12 (2), pp. 103-120, Ago. 2019

SOUZA JÚNIOR, J. A. Refrigerantes: uma proposta temática para o ensinoaprendizagem de Química na educação de Jovens e Adultos - EJA. 2015. 56 f. Trabalho de Conclusão de Curso II (Graduação) - Universidade Estadual de Goiás, Campus Ciências Exatas e Tecnológicas Henrique Santillo, Anápolis, 2015.

TAHA, M. S.; LOPES, C. S. C.; SOARES, E. L.; FOLMER, V. Experimentação como ferramenta pedagógica para o ensino de Ciências. Experiências em Ensino de Ciências. v. 11, n. 1, p. 138-154, 2016.

TOMAZ, M.; RAMOS, A. A. M.; MENDES, L. L. Consumo de refrigerantes e fatores relacionados aos hábitos alimentares de crianças e adolescentes de escolas municipais da região nordeste de Juiz de Fora. HU Revista. v. 40, n. 3 e 4, p. 189-194, 2014.

VEIGA, G. V.; CUNHA, A. S.; SICHIERI, R. Trends in overweight among adolescents living in the poorest and richest regions of Brazil. American Journal of Public Health. v. 94, n. 9, p. 1544-1548, 2004.

WILLETT, W. C. Eat, drink, and be healthy: the Harvard Medical School guide to healthy eating. 12 ed. New York: Simon and Schuster, 2001.

WILSEK, M.; TOSIN, J. Ensinar e aprender Ciências no ensino fundamental com atividades investigativas através da resolução de problemas. Estado do Paraná, v. 3, n. 5, 2012. Disponível em: 〈https://bit.ly/2EL14pK〉. Acesso em: 23 junho de 2017.

WIRTH, M. Consumo de sucos e refrigerantes: um risco maior para crianças e adolescentes. Sistema Integrado de informação em Saúde, 2010. Disponível em: <https://bit.ly/2C4V8n5>. Acesso em: 30 junho de 2017.

ZANON, D. A. V.; FREITAS, D. A aula de Ciências nas séries iniciais do ensino fundamental: ações que favorecem a sua aprendizagem. Ciências \& Cognição. v. 10, p. 93 103, 2007. 
Ensino, Saúde e Ambiente - V12 (2), pp. 103-120, Ago. 2019

SOBRE OS AUTORES

\section{GILVANICE SOARES FERNANDES LOPES}

Licenciada em Ciências da Natureza pelo Instituto Federal de Mato Grosso (IFMT), Campus São Vicente em 2018, atua como docente em escola estadual no ensino fundamental. Este artigo faz parte de seu trabalho de conclusão do curso, onde participou efetivamente do desenvolvimento das atividades, coleta de dados e escrita do artigo.

\section{JULIO DA SILVA OLIVEIRA}

Licenciado em Ciências da Natureza pelo Instituto Federal de Mato Grosso (IFMT), Campus São Vicente em 2018, foi bolsista do PIBID durante grande parte da graduação. Este artigo faz parte de seu trabalho de conclusão do curso, que desenvolveu junto com a primeira autora, onde participou efetivamente do desenvolvimento das atividades, coleta de dados e análise e discussão dos resultados.

\section{LEANDRO CARBO}

Graduado em Química e Mestre em Saúde e Ambiente pela Universidade Federal de Mato Grosso (UFMT), Doutor em Química pela UNESP, docente do Instituto Federal de Mato Grosso (IFMT), Campus São Vicente e membro do quadro docente do Mestrado em Ensino (IFMT/UNIC). Orientou o trabalho desenvolvido pelos dois primeiros, tanto no planejamento da pesquisa, quanto do desenvolvimento e escrita do artigo.

\section{ANDRÉ BERTON}

Graduado em Química e Mestre em Recursos Hídricos pela Universidade Federal de Mato Grosso (UFMT), docente do Instituto Federal de Mato Grosso (IFMT), Campus São Vicente. Participou efetivamente da avaliação do trabalho e auxiliou na confecção, análise e discussão dos resultados da pesquisa desenvolvida.

\section{EDIONE TEIXEIRA DE CARVALHO}

Licenciada em Geografia pela Faculdade de Educação Ciências e Letras de Iporá e Doutora em Ciências Pedagógicas pela Universidad Central Marta Abreu de Las Villas - Cuba (2007), revalidado no Brasil pela UFBA, docente do IFMT e membro do quadro docente do Mestrado em Ensino (IFMT/UNIC). Participou efetivamente da avaliação do trabalho e auxiliou na confecção, análise e discussão dos resultados da pesquisa desenvolvida. 